\title{
Exploring Adoption of Smart Glasses: Applications in Medical Industry
}

\author{
Müge Göken ${ }^{1}$, A. Nuri Başoğlu ${ }^{1}$, Marina Dabic ${ }^{2}$ \\ ${ }^{1}$ İzmir Institute of Technology, Department of Industrial Design, İzmir, Turkey \\ ${ }^{2}$ Nottingham Trent University, Nottingham, England
}

\begin{abstract}
This research is a study exploring the utilization of smart glasses by physicians and their adoption to these products in medical industry. Although varied smart glasses were examined in the process by literature review, in whole work M100 was used as a physical product. In this research study, three research methods were applied. These are semi-structured in-depth interview, expert focus group work and experimental study. 95 constructs were extracted from literature review and interviews by physicians. Approximately 40 most significant constructs were selected by physicians in the expert focus group work. At the end, 75 physicians answered a survey related with these 40 constructs. Furthermore, these constructs include the most significant design inputs of smart glasses for the expert group. The survey included approximately 50 questions. According to survey and results of multiple regression analyses; it is revealed that compatibility, ease of reminding, speech recognition and ease of use affect usefulness positively. Moreover, ease of learning, ease of medical education, external influence and privacy affect ease of use positively too. In addition, usefulness, ease of use affect attitude and attitude affects intention. To sum up, designers should focus on these design inputs at the first stage of product development process of smart glasses for physicians.
\end{abstract}

\section{INTRODUCTION}

In this study, adoption of smart glasses in medical industry was examined. The reason why physicians were selected as a target market was many articles show that physicians were the first adopters of smart glasses. Moreover, these researches display that smart glasses would have wide application area in health industry.

\section{A. Definition and Significance of the Problem}

Muensterer et al. [18] explained that "Glass has some clear utility in the clinical setting; however, before it can be recommended universally for physicians and surgeons, substantial improvements to the hardware are required, issues of data protection must be solved, and specialized medical applications (apps) need to be developed".

As Muensterer et al. [18] mentioned smart glasses need improvements for usage by physicians. These needs are the problems of the research. Furthermore, solving of these problems is significant for adoption of smart glasses by physicians and diffusion of these products in the medical market.

\section{B. Goal of the Study}

The aim of the study was to examine significant design parameters of smart glasses for usage by physicians in depth. Furthermore, the second goal of the research is to find the order of importance of these design parameters for the user. It is expected that this research would assist designers, engineers, $R \& D$ workers in the product development process of smart glasses.

\section{Outline of the Study}

In Introduction section, the aim and the structure of the study was mentioned. A summary of literature between 2005 and 2015 about the research topic was written in Literature Review part. Additionally, in Methodology section, the methods of the research were stated. Moreover, in Findings and Discussion section, discovery was showed and discussed. Lastly, in Conclusion, meanings and implications of discovery were explained.

\section{Process of the Research}

This research has started to be conducted in November in 2014. It took approximately one and a half years. Table 1 shows the detailed process of the research.

TABLE 1 DETAILED PROCESS OF THE RESEARCH STUDY

\begin{tabular}{lll}
\hline ACTIVITIES & CONTENT & DATE \\
\hline PROJECT SELECTION & Discussed nearly 50 ideas. & NOV.-DEC. 14 \\
& Narrowed down into 4 ideas. & \\
& Chosen 1 topic. & SEPT. 14- OCT. 15 \\
LITERATURE REVIEW & More than 100 academic papers were analyzed. & \\
& More than 20 websites related with topic were examined. & AUG-SEPT.15 \\
IN DEPTH INTERVIEW & More than 30 videos about topic were watched. & SEP-NOV.15 \\
EXPERT FOCUS GROUP & Interviewed with 8 people who are physicians. & \\
& 95 constructs were sent to 23 students as a pilot study. & \\
EXPERIMENTAL STUDY & 95 constructs were sent to 7 expert physicians. Most significant 41 constructs & \\
DATA ANALYSES & were chosen. & DEC. 15 \\
FINDINGS & Asked 51 questions with internet-based questionnaire.75 physicians answered. \\
CONFERENCE PAPER & IBM SPSS 20 was used. & DEC. 15 \\
& Analyses were evaluated. & DEC. 15 \\
& PICMET 16 conference paper was prepared. & FEB-APR 16 \\
\hline
\end{tabular}




\section{Proceedings of PICMET '16: Technology Management for Social Innovation}

\section{LITERATURE SURVEY}

\section{A. Technology of Smart Glasses}

Smart glass is one of the most well-known wearable technologies on the world. It basically records and monitors the environment.

The most popular one is Google Glass among smart glasses. The popular functions of Google Glass are taking picture, recording video, getting directions, sending messages, calling, Google searching.

The other well-known smart glasses are Vuzix M100. This model's main functions are recording video, taking photograph, internet searching, sending e-mail, and scanning barcodes, listening to the music, recording audio, telephoning, displaying clock, calendar, and weather forecast.

\section{B. Design Factors of Smart Glasses}

\section{Privacy}

Privacy is one of the significant issue that designer should consider while designing a smart glasses. In the articles, there are many evaluation about this topic.

Safavi et al. [24] stated that "Following the exciting first reactions, Google Glass has encountered seriously criticism, due to the perceived threats to security and privacy. Moreover, Safavi et al. [24] explained that "Cyber security is one of the most serious threats, both to private users and business enterprises. At present, Google Glass makes it easy for cyber hackers to gain access to our personal data, banking and credit card details, passwords or personal identification numbers."

\section{Hands free}

Hands free means that the product can be used without hands. Voice and gesture-controlled smart glasses can be used hands free.

Pillai [23] stated that "Touching, or even nearly touching, a sensor to interact with the system would sharply curtail the device's utility in any procedural environment. In a clinical setup, touching anything that is not sterile, whether it is the Glass or something in proximity to it, would require the doctor to change whatever touched the device such as a gown sleeve, glove or instrument".

\section{Voice control}

Voice control refers that smart glass is controlled by voice.

Brusie et al. [3] compared two well-known smart glasses; Google Glass and Vuzix M100 in terms of voice control. It seems that both glasses need some improvements about voice control applications.

\section{Battery Life}

Almost many electronic devices need longer battery life for easy usage. It is also essential for smart glasses in medical industry. Because taking break in the middle of a surgery or any significant operation could be problem for patient health.
Therefore, battery life is a significant issue that designers of smart glasses should consider while developing smart glasses.

Vorraber et al. [32] stated that low battery capacity is one of the shortcomings of Google Glass in their research paper. Vorraber et al. [32] also expressed that "in case of computational intensive tasks running on Glass, the battery life is relatively short (i.e. approximately $2 \mathrm{~h}$ )".

\section{Ergonomics}

The ergonomic of screen of smart glasses is one of the significant problems that should be solved in the product development process. Some of smart glasses need to be redesigned according to results of usability tests.

According to Bruise et al. [3] M100 has obstruction of view in the display eye. It shows that R\&D people in the companies of smart glasses should focus on ergonomic issues.

\section{Smart Glasses in Medical Industry}

Many technology researches show that smart glasses have potential application areas in medical industry. Some of them are surgery, telementoring, electronic health recording and medical education.

\section{a. Surgery}

Surgery is one of the significant medical fields which smart glasses would be placed in. The most essential reason why it has a potential usage in surgery rooms is its visual recording abilities by its camera. This camera located near the eyes. Therefore, it is easy to record a surgery by these smart glasses.

Li et al. [16] explained that "some hospitals are using Google Glass to assist surgeons by allowing them to not have to inquire constantly regarding their patient's condition during surgery".

Moreover, Muensterer et al. [18] stated that "Google Glass has some clear utility in the clinical setting, and foresee ably a great potential to favorably impact medical and surgical practitioners in their daily activities." in their original research.

These researches show that smart glasses have already started to be placed in operating rooms. Furthermore, the demand for smart glasses by surgeons will increase.

\section{b. Telementoring}

Surgeons can use smart glasses for telementoring. They can take advices from other surgeons who are not in the same town by the help of smart glasses during surgery.

Hashimoto et al. [11] mentioned that "telementoring is defined as the remote guidance of an inexperienced individual during an operation or procedure involving live, two-way audiovisual communication".

Hashimoto et al. [11] also stated that "while Google Glass provides a great breadth of functionality as a wearable device with two-way communication capabilities, current hardware limitations prevent its use as a telementoring device in 
surgery as the video quality is inadequate for safe telementoring."

It shows that smart glasses can be used as a telementoring tool during surgery. However, it needs some improvements related with hardware.

\section{c. Electronic Health Recording}

One of the essential application fields of smart glasses is electronic health recording. Smart glasses are in use by family physicians as a recording, documenting and monitoring tool.

ECRI Institute [9] mentioned that "In January 2014, Dignity Health in San Francisco began a pilot study in collaboration with software firm Augmedix to evaluate whether Google Glass could help family practice physicians redirect more time to patient care and less time to data entry for electronic health records (EHRs)".

This Augmedix software of smart glasses assists to record the dialogue between patient and physician. Furthermore, the workers of company transfer these records into text documentation by smart glasses.

This study of Augmedix Company shows that it has a significant usage potential of smart glasses in electronic health recording.

\section{d. Medical Education}

Lastly, smart glasses have started to be used in medical education. Medical students can watch surgery on video which is recorded by smart glasses outside the operating room.

Vallurupalli et al. [29] state that wearable technology has the potential to enhance medical education.

\section{RESEARCH METHODS}

In order to explore the adoption of smart glasses among physicians, three research methods have been applied. These are face to face in depth semi-structured interview, expert focus group study and experimental study (Figure 1).

Table $2 \mathrm{a}$ also shows the numbers and expertise of participants of this research.

\section{A. Literature Review and Interview}

By the help of the interview and literature review, approximately 95 essential constructs of smart glasses were conducted. Interviews were realized with 8 physicians who are working in İzmir. They have asked 12 questions about the usage of smart glasses M100. Some of constructs were conducted by these interviews. Furthermore, more than 100 academic articles about smart glasses in medical industry were analyzed and some constructs were conducted by literature review.

\section{B. Expert Focus Group Work}

Then 7 physicians were requested to choose the most significant 15 constructs for them from 95 constructs. Moreover, 23 students of computer engineering, industrial design and engineering management were requested to choose 15 construct by imagining themselves like physicians from 95 constructs. Thus, 30 people have chosen 15 constructs for usage of smart glasses in medical industry. Lastly, by utilizing Microsoft Excel program, the most preferred 41 constructs by expert focus group were determined (Table 3). These constructs includes conceptual, features and content features of smart glasses.

\section{Experimental Study}

At the end of the research, for each construct 1 to 3 items were created. In the experimental study, these 51 items related with 41 constructs were ranked by 75 physicians 1 to 5. Survey Monkey website was preferred for the survey. Then, SPSS Statistics 20 was used to analyze these answers.

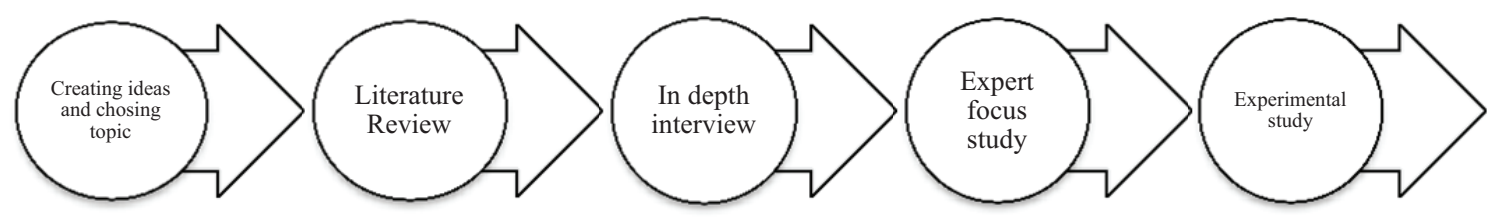

Figure 1 Process of Research

TABLE 2a NUMBERS AND EXPERTISE OF PARTICIPANTS OF THE RESEARCH.

\begin{tabular}{lcl}
\hline Methods & Number of participants & Expertise \\
\hline In-depth interview & 8 & Physicians \\
Expert Focus Group Work 1 & 23 & $\begin{array}{l}\text { Students of industrial design, computer engineering, } \\
\text { engineering management } \\
\text { Expert Focus Group Work 2 }\end{array}$ \\
Experimental Study & 7 & Physicians \\
& 75 & Physicians \\
\hline
\end{tabular}


TABLE 2b TAXONOMY OF SMART GLASSES ADOPTION

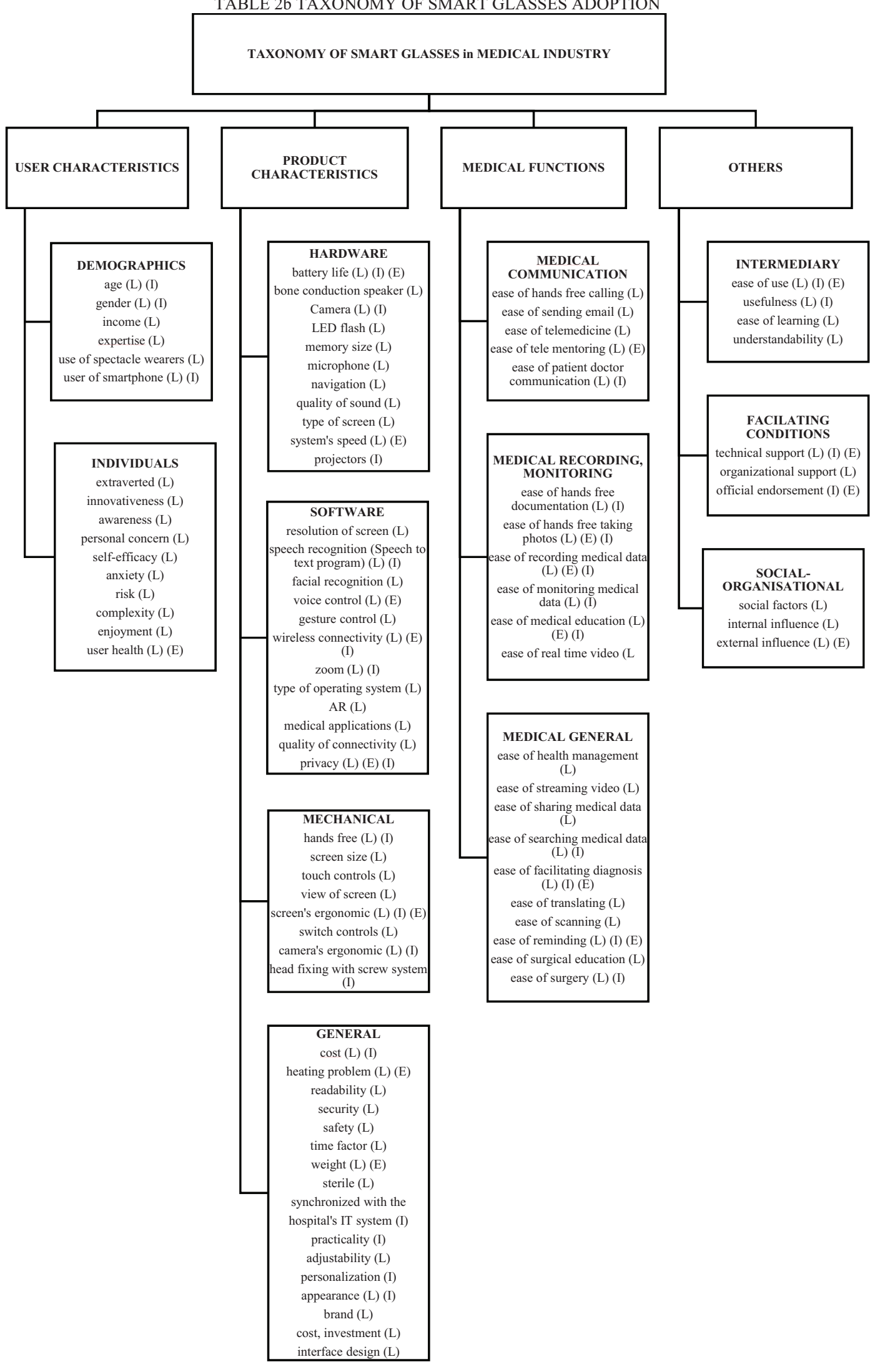




\section{FINDINGS AND DISCUSSIONS}

\section{A. Results of Literature Review and Interview}

\section{The Proposed Smart Glasses Adoption Taxonomy}

Similar to Topacan's master thesis [27], before proposing the models and the hypothesis, smart glasses health adoption taxonomy was created by using the variables collected from literature survey, qualitative studies, and expert focus group study. Table $2 \mathrm{~b}$ shows the proposed taxonomy.

In Table $2 b$ letters shown near the variables indicates source of the variable. Letter "L" represents literature survey, letter "I" refers to interview, and letter "E" denotes expert focus groups. For instance-, (L) (E) means that the variable was mentioned in both of literature survey and expert focus group.

Smart glasses health adoption taxonomy was divided into six categories, as follows "product characteristics", "user characteristics", "facilitating conditions", "socialorganizational", "medical functions", and "intermediary". Product characteristics also contain four more sub-categories, like "hardware", "software", "mechanical", and "general". All of these categories include specific variables.

\section{B. Results of Expert Focus Group Work}

In the research, 30 people assisted to narrow down 95 constructs into 41 constructs. 7 of these 30 people are physicians. The other 23 people are students who study in İzmir Institute of Technology. Their expertises are computer engineering, industrial design and management of engineering. All of the participants of expert focus group were requested to choose 15 significant constructs from 95 constructs for usage of smart glasses in medical industry. After that, 41 significant constructs were determined (Table 3).

\section{Results of Experimental Study}

In the online survey, 75 physicians were requested to rank the items 1 to 5 . There were 50 items related with 41 constructs. One of the questions was open-ended.
All participants of the survey are older than 18. The gender distribution of the study subjects was $24 \%$ females and $76 \%$ males. These physicians are all working in Turkey and they are from varied cities such as İstanbul, İzmir, Ankara, etc...In the research process, LinkedIn social platform were preferred to send surveys to these experts.

After the survey, all data were transferred into IBM SPSS Statistics 20 program. Then, many types of analyses were performed by this program. However, because of the limited time, only the results of descriptive analyses and multiple regression analyses will be mentioned in the conference paper.

\section{Findings of Descriptive Statistic Analyses}

Number of respondents, mean, standard deviation, minimum, and maximum values of the constructs were summarized in Table 4. The results of descriptive statistics reveal that participants thought that screen of smart glasses should be in accordance with the rules of ergonomics. They also preferred technical support when they are using smart glasses. Furthermore, most of participants stated that smart glasses should pay attention to patient privacy. Lastly, they expressed that the product should be adjusted according to their faces and they would like to monitor medical data by smart glasses.

\section{a-Technical Support}

Venkatesh [31] asserted that organizations should consider providing general computer training programs to increase users' computer awareness and self-efficacy.

Moreover, Wua et al. [34] pointed out that "a number of studies suggested that given valuable training programs and technical support will efficiently enhance individual capabilities and their perceptions and also increase their perceptions of system ease of use and usefulness." in their research.

Likewise Venkatesh [31] and Wua et al. [34] specified, in this research physicians stated that they care about technical support when they are using smart glasses.

TABLE 3 CONSTRUCTS CHOSEN BY EXPERT FOCUS GROUP

\begin{tabular}{|c|c|c|c|}
\hline \multirow{2}{*}{$\begin{array}{l}\text { Concept Constructs } \\
\text { Innovativeness }\end{array}$} & \multicolumn{2}{|c|}{ Feature Constructs } & \multirow{2}{*}{$\begin{array}{l}\text { Content Feature Constructs } \\
\text { Adjustability }\end{array}$} \\
\hline & Battery Life & Ease of reminding & \\
\hline Self efficacy & Weight & Ease of hands free taking photos & Screen's ergonomic \\
\hline $\begin{array}{l}\text { Ease of patient doctor } \\
\text { communication }\end{array}$ & Computer Speed & $\begin{array}{l}\text { Synchronized with the hospital's } \\
\text { system }\end{array}$ & Interface design \\
\hline Technical Support & Memory size & Ease of recording surgery & Eye health \\
\hline Privacy & Heating Problem & Ease of recording medical data & \\
\hline Compatibility & Wireless connectivity & Ease of monitoring medical data & \\
\hline Internal Influence & View of screen & Ease of sharing medical data & \\
\hline External Influence & Resolution of screen & Ease of hands free documentation & \\
\hline Ease of learning & Hands free & Ease of facilitating diagnosis & \\
\hline Ease of use & Voice control & Ease of telemedicine & \\
\hline Usefulness & Gesture control & Ease of medical education & \\
\hline Attitude & Speech Recognition & & \\
\hline Intention & & & \\
\hline
\end{tabular}




\section{b-Ease of Monitoring Medical Data}

According to results of descriptive analyses of survey, smart glasses will assist surgeons to monitor medical data. In the original research, Vorraber et al. [32] stated that "the interventionalists reported that Google Glass improved concentration on the task in hand by reducing head and neck movements (which would be needed to view several remote monitors)".

Similar to Vorraber's [32] research, Jalaliniya and Pederson [13] also emphasized that it is easier for surgeons using smart glasses as a monitor in the surgery. They gave an example about the monitoring medical data by smart glasses.

Jalaliniya and Pederson [13] mentioned that "During surgery, the surgical team needs to monitor important information on a display. For example, during some orthopedic surgeries, it is necessary to take periodic x-rays of the patient (fluoroscopy). Fluoroscopic surgeries force the surgeon to frequently switch focus between the surgical site and the screen. The smart glasses can display this information directly to the surgeon's eyes, letting the surgeon maintain focus on the patient, reducing surgery time and avoiding complications from x-ray exposure."

\section{c-Ease of Recording Medical Data}

Recording medical data by smart glasses is another significant issue for medical workers.

Parviz [21] explained that "The ability of Glass to record first-person experiences enables natural and seamless recording and documentation of medical procedures so they can be retrieved at later dates, if needed."

Schreinemacher et al. [26] pointed out that "When an unexpected situation has occurred during a procedure or consultation, the recording can be reviewed and unknown or otherwise overseen relevant factors unveiled. An illustrated start for a cycle of improvement. In addition, the recording of these unexpected situations might aid in legal matters."

\section{d-Wireless connectivity}

Chai et al. [4] indicated that "Modern wireless infrastructure, miniaturization of hardware, and improved penetration of cellular phones, computers, and tablets have advanced the use of mobile technology into health-care settings."

Wireless connectivity is an essential necessity for such kind of a device in medical industry as it has already been shown in this research. However, privacy issues should be solved strictly besides connectivity. Waxman [33] explained that "Google Glass needs an open Wi-Fi network or a Bluetooth connection to a tethered cellular phone to connect to the Internet. Patient data can be loaded into 'the cloud' without encryption or security messages in place."

Actually, wireless connectivity is vital for this wearable device in medical industry. As Datta mentioned [6] use of smart glasses in medical education, telementoring, wireless connectivity is required.

Datta [6] stated that "Using local hospital resources, wireless internet, and wear- able technology we achieved the following 4 key objectives: (1) delivery of safe surgical care to underserved populations, (2) in-person training and mentoring of local surgeons, (3) remote, real-time teleproctoring of operations in under-served regions, and (4) objective international performance assessment of surgeon technical proficiency."

\section{Findings of Multiple Regressions Analyses}

Regression analysis was used to examine relationships among constructs in the smart glasses' adoption taxonomy.

After preparation of taxonomy, expert focus group had narrowed down these 95 constructs of taxonomy into 41 constructs (Figure 1). Then, 51 questions (items) were prepared according to these 41 constructs.

As it is mentioned in methodology part, 75 physicians ranked these 51 questions 1 to 5 . Then, data which were gathered from 75 physicians were sent to SPSS program. After sending data to SPSS, many types of analyses were examined. However, in this paper, descriptive and regression analyses are being stated.

Regression model of the research were executed in SPSS Statistics 20 software (Figure 2).

Although there were 41 constructs were added to the regression analyses, only relationships between 11 ones have found significant to be displayed.

TABLE 4 DESCRIPTIVE STATISTICS

DESCRIPTIVE ANALYSES (Sorted by Means)

\begin{tabular}{|c|c|c|c|c|c|c|}
\hline Constructs & $\mathbf{N}$ & Min & Max & Mean & Std. Deviation & Questions \\
\hline Screen Ergonomic & 70 & 3 & 5 & 4,73 & 0,479 & $\begin{array}{l}\text { I would like the display will be in accordance with } \\
\text { the rules of ergonomics }\end{array}$ \\
\hline Technical Support & 71 & 2 & 5 & 4,72 & 0,565 & I care about technical support when I am using it \\
\hline Privacy & 71 & 2 & 5 & 4,7 & 0,595 & I think that it should pay attention to patient privacy \\
\hline Adjustability & 70 & 3 & 5 & 4,69 & 0,498 & I would like it to be adjusted according to my face \\
\hline $\begin{array}{l}\text { Ease of Monitoring } \\
\text { Medical Data }\end{array}$ & 71 & 2 & 5 & 4,68 & 0,58 & $\begin{array}{l}\text { I would like to monitor the medical data by this } \\
\text { product }\end{array}$ \\
\hline $\begin{array}{l}\text { Ease of Recording } \\
\text { Medical Data }\end{array}$ & 71 & 3 & 5 & 4,65 & 0,537 & I would like to record medical data \\
\hline Hands free & 71 & 2 & 5 & 4,65 & 0,657 & I prefer to use hands free \\
\hline Wireless connectivity & 71 & 3 & 5 & 4,65 & 0,588 & I would like wireless connectivity \\
\hline Attitude 2 & 70 & 2 & 5 & 4,64 & 0,66 & I would like to use it \\
\hline $\begin{array}{l}\text { Ease of Medical } \\
\text { Education }\end{array}$ & 71 & 1 & 5 & 4,59 & 0,729 & I would like to use it in medical education \\
\hline
\end{tabular}


The results show that attitude is a direct determinant of users' intention toward the smart glasses with a coefficient of $.298(\mathrm{p}<.05)$. This relationship was also found significant in the previous studies [10] and [5].

Attitude is directly affected by usefulness and ease of use with the coefficients, $730 \quad(\mathrm{p}<0.001)$ and, $179 \quad(\mathrm{p}<.05)$, respectively. These variables explain .712 of the attitude. Moreover, ease of use is significantly correlated with usefulness $(b=.114, p<.05)$. These findings are parallel with what Davis found in TAM model [7].

The model revels that compatibility $(b=, 435, p<.001)$, ease of reminding $(b=, 209, p<.05)$, speech recognition $(b=, 211, p<.05)$ are direct determinants of usefulness.

Besides, the effect of ease of learning, ease of medical education, external influence and privacy on ease of use are sustained with $-, 435,322,321$ and,- 210 beta coefficients and $<.001,<.001, \quad<.001, \quad<0.05$ significant values, respectively.

\section{a. Compatibility}

Compatibility influences acceptance of smart glasses among physicians. Schaper \& Pervan [25] stated that "compatibility is the degree to which an innovation is perceived as being consistent with the existing practices, values, needs and experiences of the healthcare professional".

The question which was asked in the survey is "Is it suitable to your professional understanding to use such kind of technological devices?"

According to results of multiple regression analyses, compatibility affects usefulness positively.

\section{b. Ease of Reminding}

Ease of Reminding has the same meaning with ease of taking notifications by smart glasses. The point is physicians need to remember many significant issues on their work. It seems that this product would have ability to remind these significant issues for them.

In the survey, the question was "Would you like to use it to remind?"

Klonoff et al. [15] expressed that "Many applications for diabetes will be possible with the use of Google Glass. The most important metric for diabetes that benefits from realtime alerts to patients is hypoglycemia."

Like the diabetics, this product would assist physicians to remember significant health issues on their work.

In accordance with results, ease of reminding affects usefulness positively too.

\section{c. Speech Recognition}

One of the brilliant features of smart glasses is recording speech. Therefore, speech to text programs and speech recognition would assist physicians in electronic health recording.

In a texting in driving research, $\mathrm{He}$ et al. [12] stated that "the use of Google Glass for texting impairs driving, but its Head-Mounted Display configuration and speech recognition technology may be safer than texting using a smart phone.".

Moreover, Lv et al. [17] mentioned that "Novel emerging user interface technologies (e.g., speech recognition) have the potential to significantly affect market share in latest wearable devices such as Google glass."

In this context, in the survey, this construct was asked as "Would you like to use speech to text program?".

Results show that speech recognition affects usefulness positively.

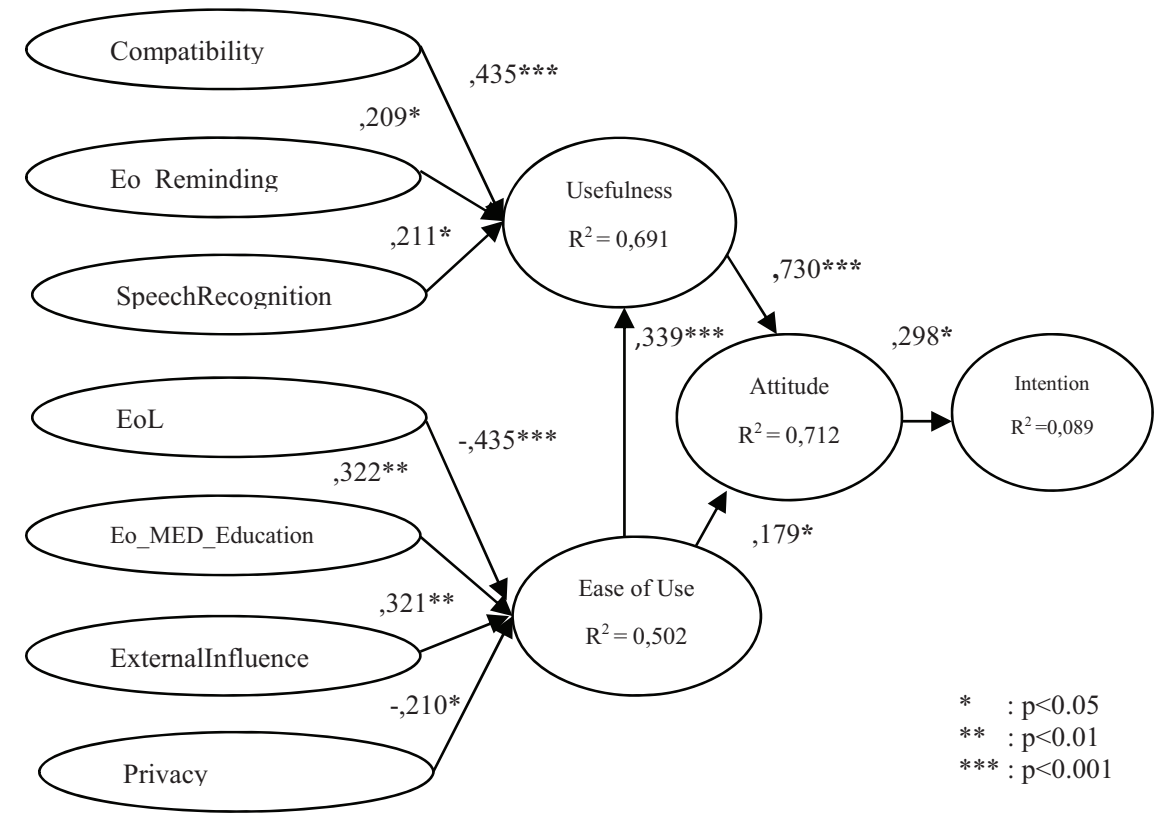

Figure 2 Result of regression model 


\section{Proceedings of PICMET '16: Technology Management for Social Innovation}

\section{d. Ease of Learning}

The question of this construct was "Do you think that it needs effort to learn use of smart glasses?" in the survey. It was a reverse question.

According to multiple regression results, ease of learning of smart glasses affects ease of use positively.

\section{e. Ease of Medical Education}

The related question was "would you like to use smart glasses in medical education?"

In accordance with results, ease of medical education affects ease of use positively.

Parslow [20] stated that "This technology allows teachers and students to share information in various modes of interaction that include flipped classrooms."

In an original research, Tully et al. [28] expressed that " In 2013, 30 second-year medical students reviewed the Google Glass video and traditional videos and then completed a post encounter, self-evaluation survey and a follow-up survey about the experience. Of the 30 students, 7 (23\%) reported a "positive, no distracting experience"; 11 (37\%) a "positive, initially distracting experience"; 5 (17\%) a "neutral experience"; and $3(10 \%)$ a "negative experience." Four students $(13 \%)$ opted to withhold judgment until they reviewed the videos but reported Google Glass as "distracting."

\section{f. External Influence}

Pedersen et al. [22] mentioned that "Findings in all research directions suggest external and social influence should be included in any adoption model applied to mobile service adoption." Similarly, external influence is located in smart glasses adoption.

The question which was asked in the survey is "Have you come across any articles that have positive approach to technological devices?"

According to results of multiple regressions, external influence affects ease of use positively.

\section{g. Privacy}

In the survey, "Would you like smart glasses pay attention to patient privacy?" was asked.

Results show that "privacy" affects ease of use positively. It means that if designers solve the privacy problems of smart glasses, ease of use of the product will increase.

There are many privacy problems related with this new technology. In many research, privacy issue is examined.

Ong [19] expressed that "Questions remain over Google Glass's ability to store confidential patient information safely. Google's marketing materials emphasize its ability to share what you are doing with others. Although this is fine for social and educational purposes, it raises concerns for patient confidentiality and privacy of healthcare records."

Furthermore, Ong [19] mentioned that "Technology companies including Google have attracted suspicion about how secure their users' records, broadcasts, and emails actually are, and about the companies' willingness to allow access to individuals' data by governments and security services."

\section{h.Usefulness}

Usefulness is one of the core constructs of TAM [7], which is a key theoretical model for technology adoption theories, and it was defined as "the degree to which a person believes that using a particular system would enhance his or her job performance" by Davis [7].

It was found in the Davis [7] research that usefulness has significant effect on behavioral intention. This finding were tested and supported by many other researchers in different contexts and situations [30], [35], [14]. Likewise, in the research, according to multiple regression results, usefulness affects attitude and consequently attitude affects intention positively.

Its questions (items) were "Is it useful?","Will it give you time?", "Does use of smart glasses let you do your job easier?", "Does use of smart glasses increase the quality of work that you have done?", "Do you think that it is useful for your work?" in the study.

\section{i. Ease of Use}

According to Davis [7], users' intention toward system use is significantly correlated with also perceived ease of use, defined as "the degree to which a person believes that using a particular system would be free of effort".

Davis [7] also stated that "ease of use is another core construct of TAM". In the TAM model, ease use strongly effects both of usefulness and behavioral intention.

In the same way, in accordance with the results, ease of use affects attitude positively, too.

Its questions were "Is it easy to use?" and "Can I do my work by this product easily?" in the survey.

\section{j. Attitude}

Fishbein and Ajzen [10] defined attitude as "the individual's positive or negative feelings about performing a behavior". Attitude toward using a system is strongly effects user intention to use the system [1], [2], [8].

Its questions were "Do you advice the other workers to use it?" and "Would you like to use it?" in the survey.

\section{k. Intention}

The question of intention was "Do you plan to use it in one year?" in the survey.

\section{CONCLUSION}

According to the study, this is clear that there need many improvements for smart glasses to be successful in the market. Especially for physicians there need some design developments.

The results of the study show that designers should integrate speech to text program into the smart glasses. It will 


\section{Proceedings of PICMET '16: Technology Management for Social Innovation}

provide recording all kind of medical data into the smart glasses and transferring them into text. Additionally, if designers improve notification programs for smart glasses, physicians will be more grateful to use such kind of a product. Thus, physicians would be able to remember significant events especially about their work by this product.

The study display that compatibility affects usefulness. This means that people who are prone to use such kind of technologies in their works would be tend to use smart glasses too.

On the other hand, ease of learning, ease of medical education, privacy and external influence affects ease of use. Designers should solve privacy issues of smart glasses. Moreover, managers should create new advertisements about this product. Making smart glasses easy to learn by additional strategies also will assist user to utilize this product easily.

Many researches show that smart glasses will have a potential use in medical education. Like them, research shows that providing ease of medical education by smart glasses will ensure ease of use for this product.

Besides the multiple regression analyses, results of descriptive analyses have implications for designer of smart glasses. In this study, participants answered questions about 41 constructs which were essential for physicians. Therefore, focusing on ten constructs were chosen mostly will be meaningful for designers at the first stage of redesigning smart glasses.

The ten constructs that are chosen mostly by physicians are screen ergonomic, technical support, privacy, adjustability, ease of monitoring medical data, ease of recording medical data, hands free, wireless connectivity, attitude and ease of medical education gradually.

Designers of smart glasses should consider ergonomic constraints, ensure technical support for user and solve privacy issues at first stage. The results show that physicians will prefer this product for monitoring, recording medical data and medical education. Therefore, designers should improve new software for these application fields.

Lastly, because of physicians prefer this product hands free and with wireless connectivity, designers should concentrate on improving voice control and connectivity properties of smart glasses.

To sum up, designers should focus on all these design parameters while designing smart glasses for medical industry.

\section{REFERENCES}

[1] Ajzen, I.; "The Theory of Planned Behavior," Organizational Behavior and Human Decision Processes, vol. 50, pp. 179-211, 1991.

[2] Bruner, G. C. and A. Kumar; "Explaining consumer acceptance of handheld Internet devices," Journal of Business Research, vol. 58, 553558. 2005

[3] Brusie, T., T.Fijal, , A. Keller, C. Lauff, K., Barker, J. Schwinck, J. F. Calland and S. Guerlain; "Usability Evaluation of Two Smart Glass Systems," Systems and Information Engineering Design Symposium, SIEDS 2015, pp. 336-341, 2015.
[4] Chai, P. R., K. M. Babu, E. W. Boyer; "The Feasibility and Acceptability of Google Glass for Teletoxicology Consults," Journal of Medical Toxicology,vol. 11, no. 3, pp. 283-287, 2015.

[5] Chau, P. Y., and P. J. Hu; "Examining a model of information technology acceptance by individual professionals: an exploratory study," Journal of Management Information Systems, vol. 18, no.4, pp. 191-229, 2002.

[6] Datta, N. , I. T. MacQueen, A. D. Schroeder, J. J. Wilson, J. C. Espinoza, J. P. Wagner, C. J. Filipi, D. C. Chen; "Wearable Technology for Global Surgical Teleproctoring," Journal of Surgical Education, vol.72, no. 6, pp. 1290-1295, 2015.

[7] Davis, F. D.; "Perceived usefulness, perceived ease of use, and user acceptance of information technology," MIS Quarterly, vol. 13, no. 3, 319-340, 1989.

[8] Dishaw, M. T., and D. M. Strong; "Extending the technology acceptance model with task-technology fit constructs," Information \& Management, vol. 36, pp. 9-21, 1999.

[9] ECRI Institute Perspectives; "Google Glass: Seeing the benefits for clinicians and patients," OR Manager, vol. 31, no. 5, pp. 20-22, 2015.

[10] Fishbein, M., and I. Ajzen; "Belief, Attitude, Intention and Behavior: An Introduction to Theory and Research," Reading, MA: AddisonWesley, 1975.

[11] Hashimoto, D. A., R. Phitayakorn, C. F. Castillo, and O. Meireles; "A blinded assessment of video quality in wearable technology for telementoring in open surgery: the Google Glass experience," Surgical Endoscopy, April, pp. 1-7, 2015.

[12] He, J., W. Choi, J. S. McCarley, B. S. Chaparro and C. Wang,; "Texting while driving using Google GlassTM: Promising but not distraction-free," Accident Analysis and Prevention. vol. 81, pp. 218$229,2015$.

[13] Jalaliniya, S., T. Pederson; "Designing Wearable Personal Assistants for Surgeons: An Egocentric Approach," PERVASIVE computing, IEEE, vol. 14, no. 3, pp. 22-31, 2015.

[14] Karahanna, E., D. W. Straub and N. L. Chervany; "Information technology adoption across time: a cross-sectional comparison of preadoption and post-adoption beliefs," MIS Quarterly, vol. 23, no. 2, pp. 183-213, 1999.

[15] Klonoff, D.C.; "New Wearable Computers Move Ahead: Google Glass and Smart Wigs," Journal of Diabetes Science and Technology, vol. 8, no. 1, pp. 3-5, 2014.

[16] Li, Y., J. Yen, and M. Hsu; "Embracing the era of wearable devices," Journal of the Formosan Medical Association, pp. 1-2, 2015.

[17] Lv, Z., L. Feng, H. Li and S. Feng; "Hand-Free Motion Interaction on Google Glass," SIGGRAPH Asia 2014 Mobile Graphics and Interactive Applications, December 03 - 06, 2014, Shenzhen, China, 2014.

[18] Muensterer, O. J., M. Lacher, C. Zoeller, M. Bronstein, and J. Kübler; "Google Glass in pediatric surgery: An exploratory study," International Journal of Surgery, vol. 12, pp. 281-289, 2014.

[19] Ong, Y. H.; "How will Google Glass change healthcare?" Student BMJ, vol. 22, pp. 5580, 2014.

[20] Parslow, G. R.; "Commentary: Google Glass: A Head-up Display to Facilitate Teaching and Learning," Biochemistry and Molecular Biology Education, vol. 42, no. 1, pp. 91-92, 2014.

[21] Parviz, B. A.; "Of Molecules, Medicine, and Google Glass," $A C M$ Nano, vol. 8, no. 3, pp. 1956-1957.

[22] Pedersen, Per E., C. Ling, C. Gilleard; "Modifying adoption research for mobile Internet service adoption: Cross disciplinary interactions," Hawaii International Conference on System Sciences, 2002.

[23] Pillai, P.; "Google Glass changing the face of medicine," http://dx.doi.org/10.13140/2.1.1253.1203, 2014.

[24] Safavi, S. and Z. Shukur; "Improving Google glass security and privacy by changing the physical and software structure," Life Science Journal, vol. 11, no. 5, pp. 109-117, 2014.

[25] Schaper, L. K., and G. P. Pervan; "ICT and OTs: A model of information and communication technology acceptance and utilization by occupational therapists," International Journal of Medical Informatics, vol. 76, pp. 212-221, 2007.

[26] Schreinemacher, M. H., M. Graafland, M. P. Schijven; "Google Glass in Surgery," Surgical Innovation, vol. 21, no. 6, pp. 651-652, 2014. 


\section{Proceedings of PICMET '16: Technology Management for Social Innovation}

[27] Topacan, U.; "Exploring the Adoption of Technology Assisted Services in the Health Care Industry," Unpublished master's thesis, Bogazici University, Istanbul, Turkey, 2009.

[28] Tully, J., C. Dameff, S. Kaib, and M. Moffitt; "Recording Medical Students' Encounters with Standardized Patients Using Google Glass: Providing End-of-Life Clinical Education," Academic Medicine, vol. 90, no.3, 314-316, 2015.

[29] Vallurupalli, S., H. Paydak, S. K. Agarwal, M. Agrawal and C. AssadKottne; "Wearable technology to improve education and patient outcomes in a cardiology fellowship program- a feasibility study," Health Technology, vol. 3, pp. 267-270, 2013.

[30] Venkatesh, V., and F. D. Davis; "A theoretical extension of the technology acceptance model: Four longitudinal field studies," Management Science, vol. 46, no.2, pp. 186-204, 2000.

[31] Venkatesh V.; "Determinants of perceived ease of use: integrating control, intrinsic motivation, and emotion into the technology acceptance model," Inform. Syst. Res. vol. 11, no. 4, pp. 342-365, 2000

[32] Vorraber, W., S. Voessner, G. Stark, D. Neubacher, S. DeMello, A. Bair; "Medical applications of near- eye display devices ," An exploratory study, International Journal of Surgery, vol. 12, pp. 12661272,2014

[33] Waxman, B. P.; "Google Glass: a new dimension in surgical education or just another gimmick?" ANZ Journal of Surgery, vol. 84, no. 11, pp. $810,2014$.

[34] Wua, J., S. Wanga, L. Lind; "Mobile computing acceptance factors in the healthcare industry: A structural equation model," International Journal of Medical Informatics, vol. 7, no. 6, pp. 66-77, 2007.

[35] Yu, P., Li, H., and M. P. Gagnon; "Health IT acceptance factors in long-term care facilities: A cross-sectional survey," International Journal of Medical Informatics, vol. 78, no. 4, pp. 219-229, 2009. 